Masyarakat Berdaya dan Inovasi

2 (2), 2021, 150 - 158

Available online: https://mayadani.org/index.php/MAYADANI

\title{
Peningkatan Minat dan Skill Kewirausahaan Mayarakat di Kelurahan Bukit Batrem, Kota Dumai
}

\section{Increasing Community Entrepreneurship Interest and Skills in Bukit Batrem Village, Dumai City}

\author{
Desyanti $^{1}$, Febrina Sari $^{2}$, Wetri Febrina ${ }^{3}$, M. Arif ${ }^{4}$ \\ ${ }^{12}$ Prodi Teknik Informatika STT Dumai, Jl. Utama Karya, Bukit Batrem, Dumai Tim., Kota Dumai, Riau 28826 \\ ${ }^{34}$ Prodi Teknik Industri STT Dumai, Jl. Utama Karya, Bukit Batrem, Dumai Tim., Kota Dumai, Riau 28826 \\ Email : desyanti734@gmail.com. Hp.082163160305
}

Received: 31 September 2021; Revision: 20 Oktober 2021; Accepted: 15 November 2021

\begin{abstract}
Abstrak
Tingginya tingkat pengangguran terbuka berpotensi meningkatkan jumlah penduduk miskin di Indonesia. Karena itu pemerintah berupaya untuk mendorong masyarakat untuk berwirausaha dengan cara mempermudah birokrasi pendirian usaha kecil menengah (UKM) dan industri rumah tangga. Kredit-kredit berbunga rendah dan bantuan keuangan juga diberikan untuk mendorong pertumbuhan ekonomi masyarakat. terlebih pada masa pandemi Covid19 ini, pembatasan gerak masyarakat sangat memperlemah jumlah transaksi jual beli. Karena itu campuir tangan akademisi sangat diperlukan, diantaranya dengan mengadakan mata kuliah Pendidikan Kewirausahaan, event Enterpreneur Award yang diikuti mahasiswa, dan kegiatan pengabdian masyarakat yang dilakukan oleh dosen perguruan tinggi. Kegiatan pengabdian masyarakat ini bertujuan untuk memberi pembekalan ilmu manejerial dan e-commerce bagi para wirausahawaan maupun calon wirausahawan yang ada di Kelurahan Bukit Batrem, Kecamatan Dumai Timur, Kota Dumai. Manfaat dari kegiatan ini masyarakat kelurahan Bukit Batrem mampu mengembangkan usahanya menjadi lebih baik dan memiliki profitabilitas yang lebih tinggi.
\end{abstract}

Kata Kunci: Wira Usaha, E-Commerce, UKM, Industri Rumah Tangga

\begin{abstract}
The high level of open unemployment has the potential to increase the number of poor people in Indonesia. Therefore, the goverrment seeks to encourage people to become entrepreneurs by simplifying the bureaucracy for the establishment of small and medium enterprises and home industries. Low-interest loans and financial assistance are also provided to encourage community economic growth. Especially during this pandemic of Covid19, restrictions on community movement have greatly weakened the number of buying and selling transactions. Therefore, academic intervention is needed, including by holding Entrepreneurship Education courses, Entrepreneur Award events that attended by students, and community service activities carried out by university lecturers. This community service activity aims to provide managerial knowledge and e-commerce for entrepreneurs and prospective entrepreneurs in Kelurahan Bukit Batrem, Kecamatan Dumai Timur, Kota Dumai.. The benefit of this activity is that the people of the Bukit Batrem are able to develop their business for the better and have higher profitability.
\end{abstract}

Keywords: Entrepreneur, E-Commerce, Home Industry

How to Cite: Desyanti, D., Sari, F., Febrina, W., \& Arif, M. (2021). Peningkatan Minat dan Skill Kewirausahaan Mayarakat di Kelurahan Bukit Batrem, Kota Dumai. Masyarakat Berdaya dan Inovasi, 2(2). doi:https://doi.org/10.33292/mayadani.v2i2.74 


\section{PENDAHULUAN}

Kewirausahaan merupakan salah satu dimensi penting dalam membentuk jiwa pemuda Indonesia, disamping jiwa kepemimpinan dan kepeloporan sebagaimana termuat dalam Tujuan Pembangunan Kepemudaan pasal 3, Undang- Undang (UU) No.40 Tahun 2009. Kewirausahaan pemuda perlu dikembangkan untuk mendorong kemandirian pemuda dibidang ekonomi, mengingat tingkat pengangguran di Indonesia saat ini masih cukup tinggi. Berdasarkan data BPS, Angkatan kerja Indonesia pada Maret 2021 sebanyak 138,22 juta orang, dan Tingkat Pengangguran Terbuka (TPT) Maret 2021 sebesar 7,07 persen atau setara dengan 9,77 juta jiwa menurut data dari BPS. Data tersebut juga dibandingkan dengan TPT dan data mengenai pelaku usaha di Kelurahan Bukit Batrem yang juga rendah menurut laporan BPS Kota Dumai yang diambil dari laporan Dumai Dalam Angka 2020.

Tingkat Pengangguran Terbuka (TPT) meningkat salah satunya disebabkan oleh lemahnya jiwa wirausaha di Indonesia adalah cara pandang yang keliru tentang dunia wirausaha. Banyak yang beranggapan berwirausaha memerlukan modal besar, pendapatan tidak pasti tiap bulannya, waktu kerja yang lebih lama dari jam kantoran, hingga kurangnya pengalaman dalam berwirausaha menjadi sebuah batu sandungan bagi seseorang untuk membuka usaha secara mandiri. Hal-hal yang sifatnya paradigma tersebut perlahan mengikis keinginan setiap orang untuk berwiraswasta, selain masalah modal, kesenjangan sosial menjadi salah satu masalah pemuda dalam berwirausaha. Seorang wirausaha selalu dianggap remeh oleh masyarakat. Kondisi ini yang menjadi permasalahan di kelurahan Bukit Batrem, Kecamatan Dumai Timur Kota Dumai. Selain itu, pemasaran wirausaha yang telah memiliki usaha belum dipasarkan secara maksimal. Belum banyak pengelola suatu usaha atau bisnis yang memanfaatkan media online sebagai alat untuk memasarkan produknya agar lebih dikenali masyarakat. Padahal dengan memanfaatkan media online sebagai media untuk memasarkan produk akan memberikan banyak manfaat (Buchari, 2010), (Dewi, 2017), (Kurniati, 2015).

Manfaat yang didapatkan diantaranya masyarakat dapat mengetahui produk yang ditawarkan dengan mudah, bagi calon pembeli dapat melakukan perbandingan dengan produk lain sebelum melakukan transaksi pembelian, peluncuran atau promosi produk baru bisa dilakukan seefektif mungkin meminimalkan biaya promosi, dan jangkauan pasar atau pangsa menjadi tak terbatas karena bisa diakses darimana saja dan oleh siapa saja (Arif \& Desyanti, 2021).

Wirausahawan adalah seseorang yang mengembangkan produk baru atau ide baru dan membangun bisnis dengan konsep baru. Dalam hal ini, menuntut sejumlah kreativitas dan sebuah kemampuan untuk melihat pola-pola dan trend-trend yang berlaku untuk menjadi 
seorang wirausahawan. Namun, masih banyak yang kurang kreatif dan tidak berani mengambil resiko untuk membuka dan mengelola usaha. Kreatif dan keberanian mengambil resiko merupakan kepribadian wirausaha. Beberapa kepribadian wirausaha lainnya seperti percaya diri, berorientasi pada hasil, kepemimpinan, kerja keras, dan masih banyak lagi, akan mendukung terbentuknya sumberdaya manusia yang mampu mengelola usaha.(Eka Apriliyanti, 2011). Hal yang paling mendorong seseorang untuk memasuki karir wirausaha adalah adanya (1) personal attributes dan (2) personal environment. Hasil-hasil penelitian menyebutkan bahwa minat berwirausaha dipengaruhi oleh potensi kepribadian wirausaha dan lingkungan.(Buchari, 2010).

Adapun tujuan pelaksanaan kegiatan PPM ini nantinya akan memberikan manfaat bagi tim STT Dumai untuk dapat menyebarkan ilmu pengetahuan tentang kegiatan memulai bisnis dan berwirausaha untuk meningkatkan ekonomi keluarga. Serta bagi mitra memiliki anggota masyarakat yang memahami semangat berwirausaha.

\section{METODE}

Metode pelaksanaan pada Pengabdian Pada Masyarakat ini adalah dengan mengadakan pelatihan kewirausahaan bagi warga Kelurahan Bukit Batrem dalam jangka waktu 1 minggu. Proses pelaksanaan pelatihan tersebut antara lain.

1. Pembuatan modul pelatihan

Sebelum pelatihan dilaksanakan terlebih dahulu tim dosen membuat modul yang akan digunakan dalam mengikuti proses pelatihan.

2. Pelaksanaan Pelatihan

Pelatihan dilaksanakan di Kelurahan Bukit Batrem. Materi pelatihan diberikan oleh tim dosen. Setiap pertemuan dilaksanakan dalam waktu 90 menit, Materi Pelatihan meliputi:

a. Membangun jiwa kewirausahaan.

b. Rencana bisnis.

c. Proses produksi dalam berwirausaha.

d. Perencanaan model bisnis online.

Proses kegiatan pengabdian ini dapat dilihat dari diagram alir sebagai berikut: 


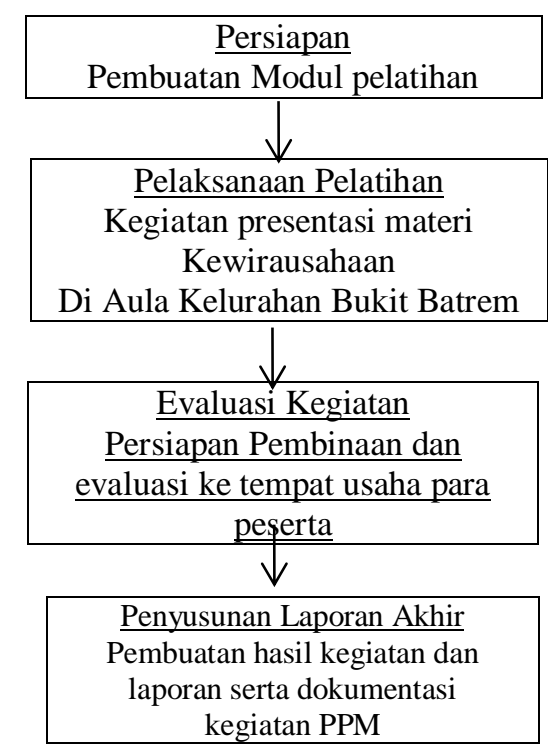

Gambar 1. Proses Kegiatan Pengabdian di Kelurahan Bukit Batrem

\section{HASIL DAN PEMBAHASAN}

Pelaksanaan kegiatan PPM ini dengan judul "Peningkatan Minat dan Skill Kewirausahan Masyarakat Di Kelurahan Bukit batrem Kota Dumai" telah selesai dilakukan. Berikut ini merupakan hasil yang dicapai dalam pengabdian ini.

Tabel 1. Langkah, Tujuan dan Hasil Pelaksanaan kegiatan

\section{Persiapan}

\begin{tabular}{|c|c|c|}
\hline Langkah & Tujuan & Hasil \\
\hline Pembentukan panitia kegiatan & $\begin{array}{l}\text { Membuat struktur kepanitian dan } \\
\text { pembagian tugas }\end{array}$ & $\begin{array}{l}\text { Struktur } \\
\text { terdiri dari tim dosen } \\
\text { STT Dumai }\end{array}$ \\
\hline Administrasi kegiatan & $\begin{array}{l}\text { Mengelola kegiatan dan bukti } \\
\text { pelaksanaan pengabdian }\end{array}$ & $\begin{array}{l}\text { Daftar hadir peserta dan } \\
\text { tim dosen, berita acara } \\
\text { pelaksanaan } \\
\text { pengabdian }\end{array}$ \\
\hline Pembuatan modul pelatihan & $\begin{array}{l}\text { Membuat modul untuk peserta dan } \\
\text { sebagai bahan presentasi }\end{array}$ & $\begin{array}{l}\text { Materi pelatihan : } \\
\text { Membangun jiwa } \\
\text { kewirausahaan, Rencana } \\
\text { bisnis, proses produksi dalam } \\
\text { berwirausaha, dan } \\
\text { Perencanaan bisnis online }\end{array}$ \\
\hline
\end{tabular}

\section{Pelaksanaan}

\section{Langkah}

Begitu juga data yang ada untuk Kelurahan Bukit Batrem yang menunjukan masih sedikitnya jumlah pelaku usaha

$$
\text { Tujuan }
$$

Pelaksanaan pelatihan terhadap materi kewiraushaan
Hasil

Pelaksanaan pelatihan dan praktek ke usaha yang dilakukan 


\section{Penutup}

Langkah

Tujuan

Hasil

Evaluasi kegiatan

Mengetahui dan menilai kegiatan usaha yang dilaksanakan maupun yang baru dilakukan oleh peserta

Saran untuk perbaikan

Melaporkan serangkaian

Laporan kegiatan kegiatan pengabdian

Laporan kegiatan PPM

Sumber : diolah dari hasil pengabdian

Kegiatan ini diisi dengan materi mengenai pelatihan kewirausahaan. Jumlah peserta diikuti oleh 50 orang peserta. Para peserta sangat antusias untuk mengikuti kegiatan ini, dibuktikan dengan kedatangan mereka yang tepat waktu. Antusiasme juga terlihat dalam mendengarkan penjelasan dari pemateri dan banyaknya pertanyaan yang diajukan seputar materi yang diberikan. Walaupun diakhir sesi kegiatan disediakan waktu khusus untuk tanyajawab, namun beberapa peserta juga mengajukan pertanyaan disela-sela materi diberikan. Materi diberikan dalam tiga sesi dan diakhiri dengan sesi tanya jawab. Materi pertama adalah membangun jiwa kewirausahaan yang disampaikan oleh Aidil Abrar, M.T. Pada materi ini dijelaskan sifat-sifat unggul wirausaha, ciri wirausaha yang berhasil, penyebab hilangnya motivasi, dan kebiasaan manusia yang efektif

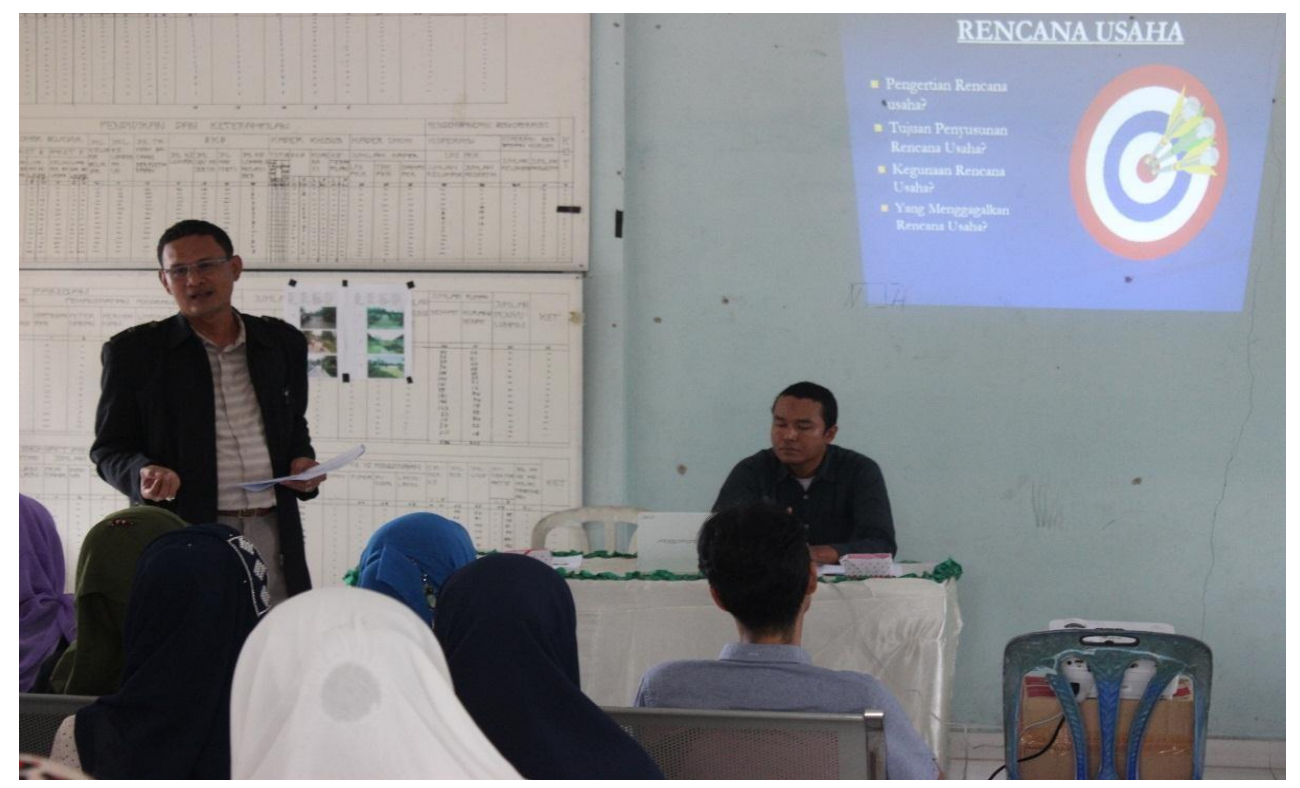

Gambar 1. Pemateri Memberikan Pelatihan 


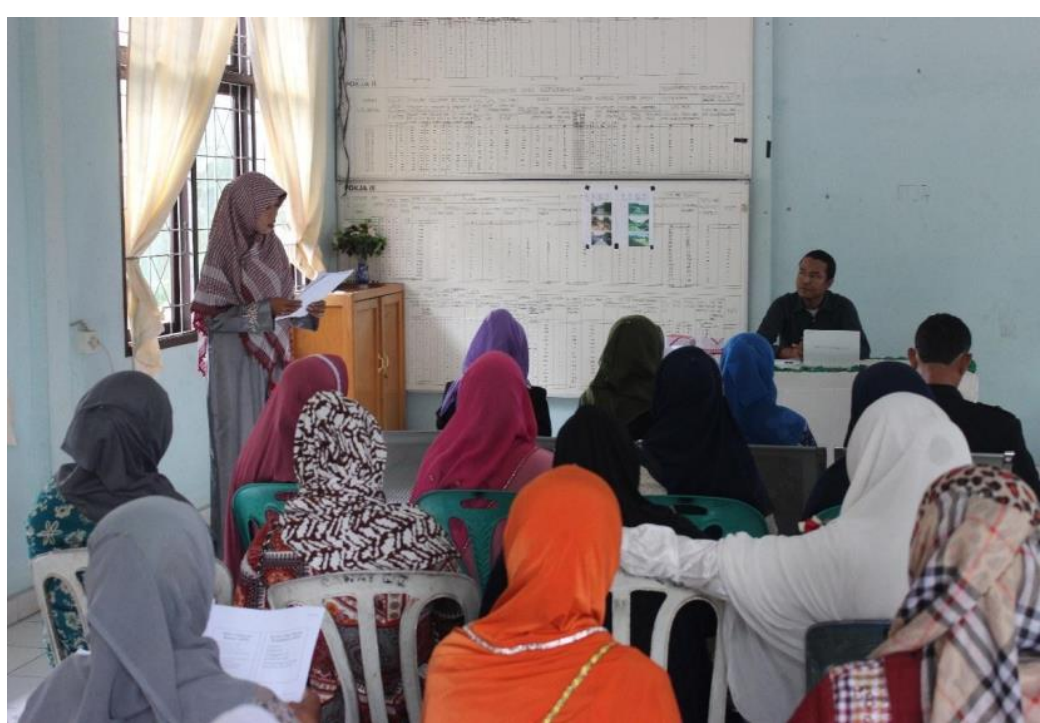

Gambar 2. Pelaksanaan Kegiatan Pelatihan

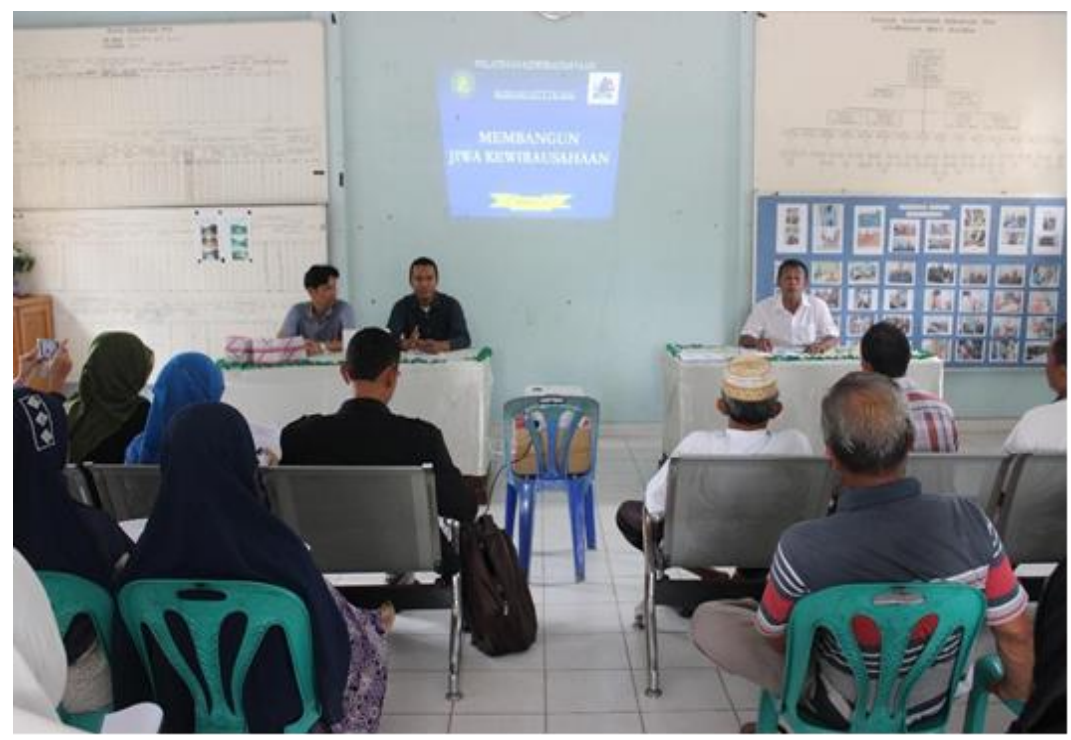

Gambar 3. Pelaksanaan Kegiatan Pelatihan

Materi kedua disampaikan oleh Muhammad Arif, M.T. Pada materi ini dijelaskan prinsip rencana usaha, proses dan tahapan rencana bisnis, tahap memformulasikan tujuan bisnis, tahap keputusan bisnis, dan ringkasan proyek usaha, Materi ketiga disampaikan oleh Ir. Yusrizal, MM.,IPM. Pada materi ini dijelaskan ciri produksi dalam berwirausaha, sumber kewirausahaan, bagaimana memanfaatkan peluang usaha, produksi dalam usaha kecil, manajemen produksi usaha kecil, dan tahap penemuan ide.

Materi keempat disampaikan oleh Desyanti, M.Kom. Pada materi ini dijelaskan bagaiman bisnis online dan aplikasi yang mendukung untuk menjadi media online dengan memanfaatkan e-commerce.

E-commerce setidaknya memberikan enam buah dampak positif bagi operasi bisnis suatu perusahaan Keenam dampak tersebut yaitu: meningkatkan efisiensi, penghematan biaya, 
memperbaiki kontrol terhadap barang, memperbaiki rantai distribusi (supply chain), membantu perusahaan menjaga hubunganyang lebih baik terhadap pelanggan dan membantu perusahaan dalam menjaga hubungan yang lebih baik terhadap pemasok. (Budi \& Fensi, 2018), (Marini, 2020).

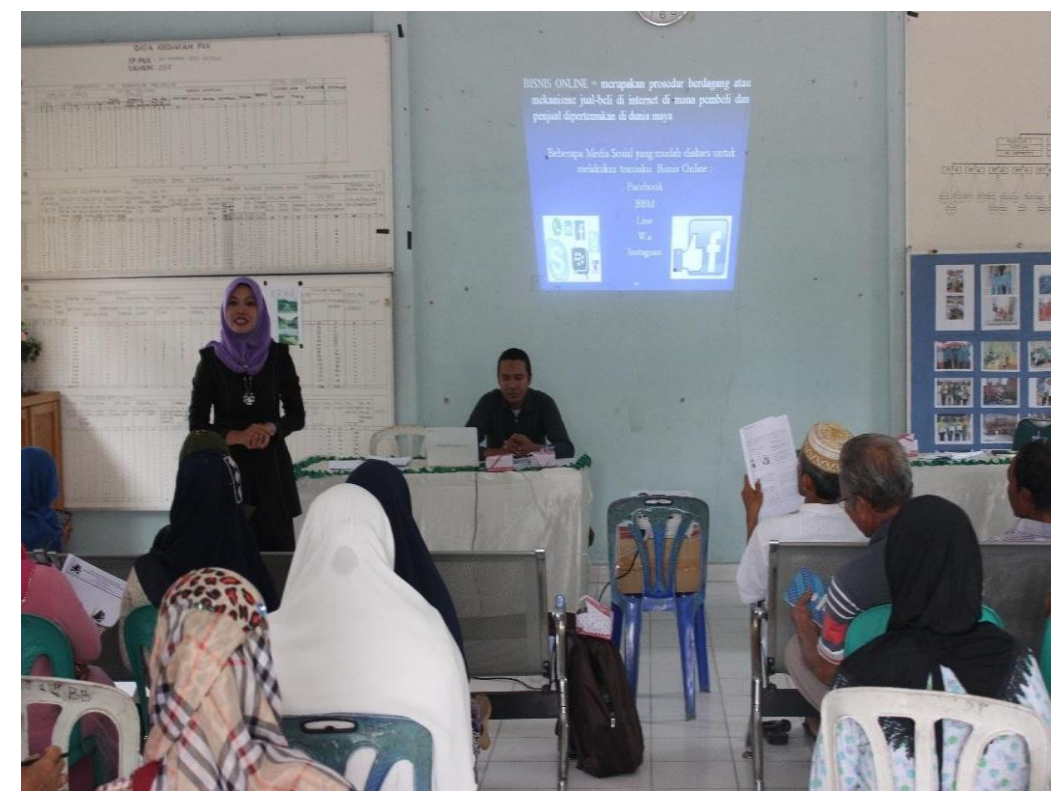

Gambar 4. Pelaksanaan Kegiatan Pelatihan

Sesi terakhir kegiatan pengabdian ini adalah sesi Tanya jawab. Disini para peserta secara aktif mengajukan pertanyaan yang berkaitan dengan media online, terutama aplikasi OLX, dan pemasaran online melalui portal e-commerce. Beberapa pertanyaan yang diajukan misalanya kelebihan dan kelemahan melakukan pemasaran online, kendala dalam melakukan jual beli online, dan bagaimana cara mencari tempat pemasaran.

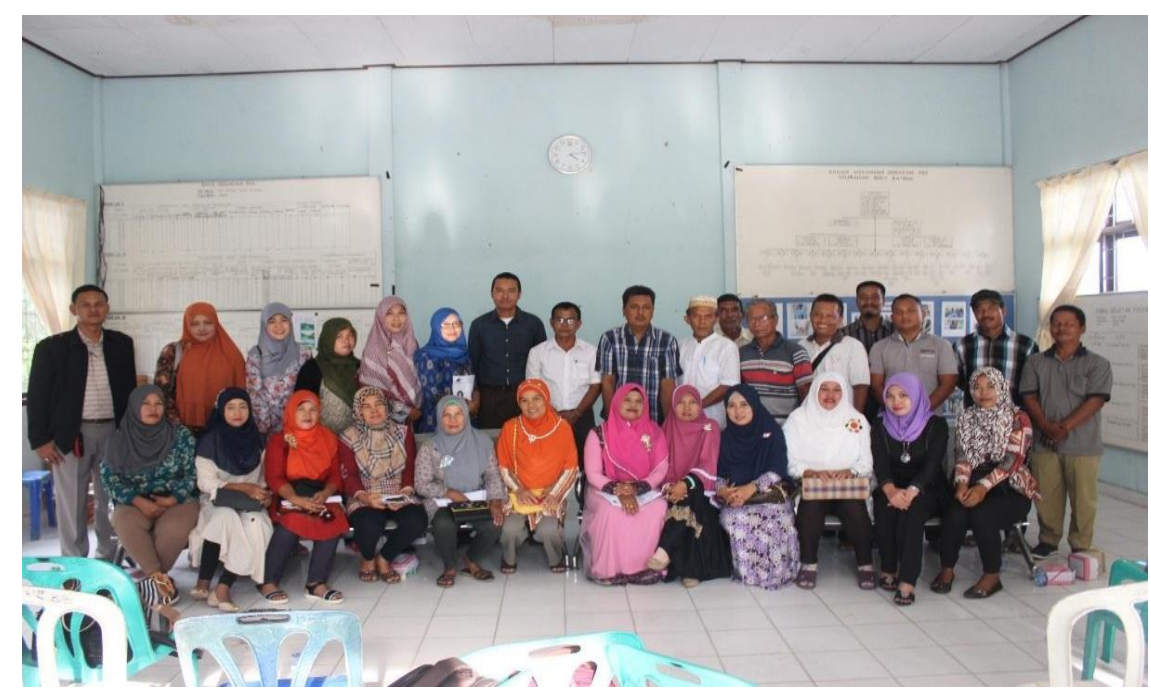

Gambar 5. Foto Bersama Setelah Pelatihan 
Pelatihan kewirausahaan dilakukan bagi masyarakat Kelurahan Bukit Batrem untuk dapat berperan serta dalam dunia usaha terutama industri kecil. Peserta dapat merancang prinsip rencana usaha, proses dan tahapan rencana bisnis, tahap memformulasikan tujuan bisnis, tahap keputusan bisnis. Menuntun peserta menggunakan dan menjadi bagian dari komunitas dalam media online sudah menjadi kebutuhan dalam bersosialisasi. Hal ini sudah menjadi poin positif bagi peserta karena mampu menjaring pertemanan dengan banyak orang dan berusaha membangun relasi bisnis dengannya. Setelah diawali pelatihan dengan beberapa materi kewirausahan yang memancing minat dan skill masyarakat untuk berwirausaha, maka kegiatan juga dilanjutkan dengan pembimbingan dan pengevaluasian beberapa usaha yang telah dan akan dilakukan oleh peserta PPM ini. Peserta juga telah merasakan manfaat dari pengarahan minat dan skill mereka sesuai bidang usaha yang dilaksanakan setelah pelatihan berlangsung. Sehinggabermanfaat untuk mengenalkan dan menawarkan produk yang dihasilkan oleh setiap usaha yang dilakukan oleh peserta sebagai mitra kegiatan ini. Kedepannya, diperlukan suatu pelatihan yang lebih mendalam untuk meningkatkan peran aktif berbagai pihak dalam ikut mengatasi masalahmasalah yang muncul dalam dunia usaha terutama industri kecil. Pelatihan yang dapat diselenggarakan bisa mengarah tentang bagaimana pengelolaan hubungan pelanggan dengan usaha yang dijalankan. Sehingga akan semakin memaksimalkan pengelolaan suatu usaha bisnis peserta dan dapat bersaing dalam menghadapai pasar global.

\section{UCAPAN TERIMA KASIH}

Terima kasih kami ucapkan pada Lurah Bukit Batrem, Kecamatan Dumai Timur, Kota Dumai, Provinsi Riau, yang sudah mendukung dan memfasilitasi pelaksanaan kegiatan pengabdian pada masyarakat ini

\section{DAFTAR PUSTAKA}

Arif, M., \& Desyanti, D. (2021). Pelatihan Kewirausahaan Bina Bisnis Pembuatan Pot Bunga Kekinian Untuk Masyarakat Perumahan Baruna. ABDINE: Jurnal Pengabdian Masyarakat, 1(1), 8-13. https://doi.org/10.52072/abdine.v1i1.160

Buchari, A. (2010). Kewirausahaan. Alfabeta.

Budi, B., \& Fensi, F. (2018). Pengaruh Pendidikan Kewirausahaan Dalam Menumbuhkan Minat Berwirausaha. Jurnal Pengabdian Dan Kewirausahaan, 2(1), 1-9. https://doi.org/10.30813/jpk.v2i1.1128

Dewi, S. K. . (2017). Konsep dan Pengembangan Kewirausahaan di Indonesia, Deepublish. 
Eka Apriliyanti. (2011). Pengetahuan Kewirausahaan, Dan Lingkungan the Effect of Entrepreneur Personality, Entrepreneurship Knowledge, and Environment on Entrepreneurial Interest. 311-324.

Kurniati, E. . (2015). Kewirausahaan Industry, Deepublish.

Marini, S. (2020). Implementasi Web Elektronik (E-Commerce) Di Toko Pecah Belah Center Dalam Meningkatkan Persaingan Bisnis Perdagangan. JPTI (Jurnal Pendidikan Teknologi Informasi, 4(1), 83-90. 